\title{
Occupation of Public Space in Socioeconomic Mobility
}

\author{
Sigit Prawoto ${ }^{1}$, Efrizal $^{2}$ \\ \{prawoto@ub.ac.id ${ }^{1}$, efrizal@ub.ac.id ${ }^{2}$ \} \\ Universitas Brawijaya, Indonesia ${ }^{1,2}$
}

\begin{abstract}
The research aimed to examine the symbolic representation in the forms of pictures and writings on the tailgates. These images and writings have been observed and interpreted semiotically, for which is a science whose main domain is the interpretation of symbols. This research found that these images have some impacts on society, considering that the existence of the trucks that have various pictures and writings passes every day on the streets. The findings show that the freedom of expression in public space is guaranteed by law, especially in the terms of freedom of expression on the road. The truck drivers express this freedom on the vehicles they drive and paying attention to several restrictions, such as not posting pictures containing pornographic and provocative elements, not installing pictures on the right and left mirrors, and not posting pictures that can block the driver's view. The pictures and writings installed on the tailgate are a form of individual expression of the driver and the vehicle owner as well, as a technique to publicize their identity. It is important to show the identity to inform the public of their characteristics, economic activities, and position in society.
\end{abstract}

Keywords: Symbolic Representation, Semiotics, Truck Tailgate, Public Space, Identity, Socioeconomic Activity

\section{Introduction}

Every person will always use the road to support their daily activities. The situation makes the road a public space full of meetings of various activities that can be understood as related to economic, educational, religious, social, political issues, and even security. To accelerate these activities, someone will take advantage of the road to facilitate mobility.

The mobility is so high that the number of vehicles passing on a road is also numerous. Each driver has a different character in driving the vehicle and the ride is also showing different characteristics from one to another. We can understand the different appearances of those vehicles from the various kinds of accessories installed on the vehicle such as; picture stickers, writing, and various color. These various appearances provide an eye-catching sight and often tempt people to pay more attention.

We often see some interesting pictures and writings among the motorized vehicle appearances, especially those on the tailgate of a truck. The pictures and writings often seem provocative and considered vulgar by some people, but there are also some pictures and writings that contain a piece of advice. Preliminary observations found that there was a difference of acceptance in society to the phenomenon; some people accepted it and refused it, with some other people seeing the phenomenon as normal. The observation of the regulations related to road traffic and transportation did not find any rules that strictly regulate the existence of these 
pictures and writings. There is only a restriction to not putting the picture that can block the driver sight.

The picture and writings on the tailgates represent something else. The pictures and writings are a sign that needs to be interpreted. There will always be something specials behind it, for a thing can be a sign as long as people think it represents something else. We interpret the thing as a sign because said Chandler [1], "We unconsciously associate this object with a convention that takes place in society". Research in semiotics has a wide coverage area and its existence is growing rapidly considering that a text is a sign, and as a sign, Hawkes [2] says, his understanding requires interpretation. Noth [3] said that in the displayed text, there are ideas and refer to other ideas so that everything that is pictured has a past. Semiotics, said Eco [4], is mainly concerned with signs as social forces. According to Michael Riffaterre [5], the semantic work area is the transfer of a sign from one level of discourse to another, metamorphosis, and functional change.

\section{Research Method}

The image on the truck attracts the attention of everyone who sees it. The reaction of public acceptance varies; some accept it and some others reject it. The fact shows a distinctive feature in society that is interested to be interpreted scientifically. Therefore, the government needs to pay more attention to this reality. To find insight into the complexity of the phenomena, the research has been done by taking direct observations into the truck communities in Malang, Batu, and Sidoarjo in East Java. The pictures collected are so abundant but after the selection, there are about 50 pictures have been analyzed.

This study also applied an interview technique by taking direct conversations with people who are part of the community such as; the manufacturer, the driver, and the owner of the truck. This research was interviewing 10 persons in different places and situations. Researchers went to the place where the truck was made; to the workshop that specialized in car body painting and the place where the truck drivers gathered as well. In these places, we got also the explications about the prices of the services they ask for that varies according to the demand of the consumers.

After obtaining the data, this study uses the semiotic analysis method to analyze the messages inside the text that manifested in the images and writings on the tailgate. The interpretations of the researchers and the explanations of the informants during the interviews are combined to get a clearer inquiry of the messages contained in the text.

\section{Result and Discussion}

The phenomenon found on the streets is that there are many pictures and writings on the truck show symbolic appearances in the form of words and pictures. The pictures are sometimes quite provocative by featuring a photo of a woman in quite minimal cloth and accompanied by writings. These writings and pictures certainly attract the public attention.

However, not all of the pictures on the tailgates are pictures of women in skimpy clothes; there are also cartoons, animals, pictures of women in headscarves, old woman and even a young baby. This situation is certainly interesting for further insight considering that the road where 
the visual works are shown is a busy public space. As a public space, various interests, desires, hopes will meet together. Public space must be a comfortable and safe place for everyone.

The community's need to have a comfortable public space is fundamental due to the rapid changes in the social environment. Public space must have certain criteria which are said to be a place that allows the users to feel that they have their own closeness, can be accessed by anyone to move freely and they must be able to meet the needs of their users [6]. For several decades, it has been said that among urban planners, safe spaces have become a hot topic of conversation [7]. This subject need serious attention from the government, especially those who related to road regulations. The highway is not only a place for vehicles to cross but has turned into a place for interaction between road users. The rest areas built on every highway are always full of people who stop to take a break during their journey. They are people who travel far from one city to another and take a break before continuing their journey. They gather, talk each other, share the same interests, discussing common issues and even built a certain community.

With the presence of people who come from different sociocultural backgrounds, the spread of graphic images and writings on the trucks also generate some different responses. There are various responses from community who use the road and from the people who live alongside the road. There are people, who accept it and consider it a funny entertainment, but some people do not like it and feel disturbed. The observations also found that the pictures and writings varied significantly in form, type and content. In addition, the analysis of government regulations in the form of laws and regulations below it does not show that there are any special arrangements related to the setting up images on motorized vehicles.

There are several types of truck bodies in Indonesia, that is, Dump Trucks, iron frame with wooden boxes and iron plate boxes. All of which have consequences for varying prices on each tailgate. The choice of the type of truck and the truck body is accorded to the daily activities of the truck. The tailgate of the truck to transport heavy goods will different from that will be used to transport medium goods. Thus, the choice of truck body material is suited to the needs of the activity purposed.

The tailgate manufacturing process takes 3-4 months long and also depends on the complexity of the customer's request. Truck decorations or accessories also affect the processing time and the costs. After finishing the working on the body, the sticker is installed and/or the picture is painted on the truck. Therefore, the work on the tailgate must be done carefully to avoid complaints from consumers. The types of writing and image are airbrush and stickers. The design models of images and writings are different according to the consumers demand so that they provide the flexibility services for consumers to design their own images and writings.

The service to create painting and writings designs is also carried out by small and medium businesses company that specialize in providing sticker installation services and truck body painting. They have a smaller business scale than the car body companies and serve a small number of consumers in a time due to the limited production ability. These small and medium businesses run their businesses in strategic places on the side of the main road so that consumers can easily reach them. They provide airbrush painting and sticker installation services with less complex regulations which mean that they provide the design of images even though the images have a tendency to contain a pornographic look. The work of drawings and paintings in a car body company is different from that done in smaller scale business.

The truck body painting and sticker cutting carried out by this company are always follows the provisions of Government Regulation Number 34 of 2006 concerning roads. In general, the guidelines state that the installation of texts and images must meet the norms of the society and to not blocking the driver's view. The government has issued the Law No. 20 of 2009 concerning Road Traffic and Transportation in the framework of providing guidance and operation of road 
traffic and transportation that is safe, secure, orderly and smooth. With this regulation, the government defines road as a complex space that can never be separated from the daily activity of every citizen. This law binds every road user to obey the regulation.

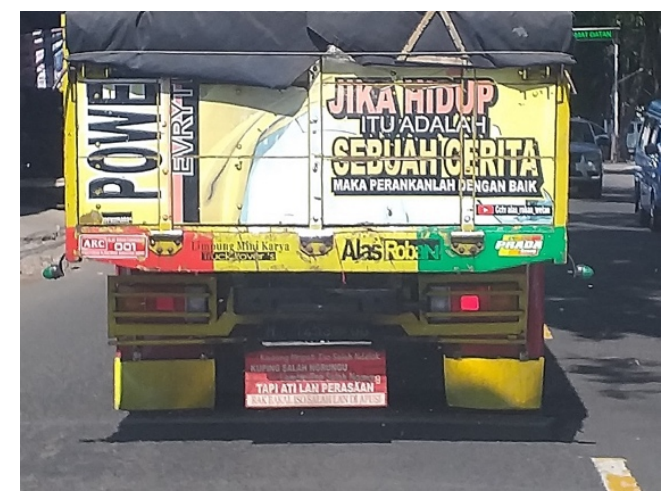

Picture 1. This truck belongs to an individual owner who is active in the services of goods transport.

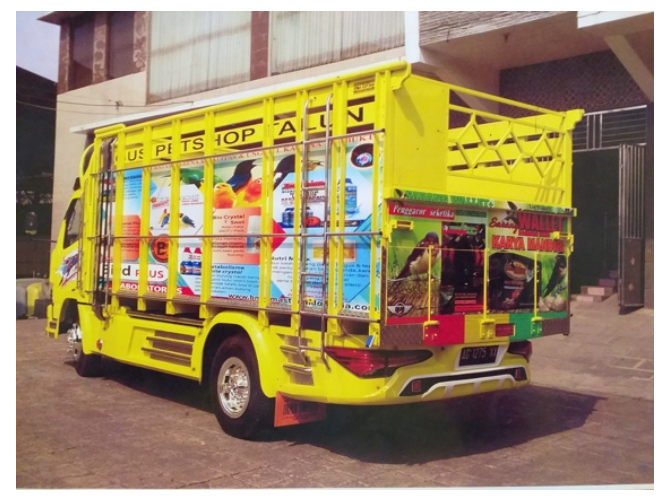

Picture 2. This truck belongs to a pet shop owner so that the pictures contain the selling object of the shop.

Source: Doc. Research team.

There is a procedure of semi-annual registration for the truck during which the Road Transport Traffic Service checks the truck. The check is including the validity of the vehicle certificate, the functioning of every vital part of the truck, the fitness of the truck to transport the number of materials, and also the appearance of the truck. In the checking of appearances, the authorities will order the driver to remove the pornographic contained pictures and other improper pictures. Because of this regulation, the drivers and the owners of the truck prefer to not installing provocative pictures to avoid allocating extra money to put and remove pictures.

Images contain a clear meaning in every use and there are the appearance of symbols [8]. It is useful for conveying messages from sender to recipient, in this case the truck driver or truck owner to the community alongside the road where the truck passes. These messages are basically intended to show that there is a truck passing and it is worth remembering.

The pictures and writings on the back of the truck are considered a natural phenomenon by the community. They are forms of sign [9] as an expression of the driver's feelings and identity. Showing their identity is important to determine their role and activities in the economic field in the society. People will recognize the picture and understood that the pictures and writings are the outpouring of the driver's expression and showing their identity and their economic activities. They know that those decorations are a kind of advertisement. The creativity to express their symbolic representations give them some benefits [10]. The public will know the owner of the truck, the activities that he performed and also the distance range of the truck, the affiliation of the truck with others and also their characteristic.

In this case, there is a question of identity that truck drivers want to establish against other drivers. There is an element of differentiation from one person to another. This selfdifferentiation is important because by being known in the public, the truck, which has the main economic function for goods transportation services will have a positive effect. The more people 
know, the higher the possibility that the public will use the transportation services. Therefore, the construction of this identity is important in running a business service.

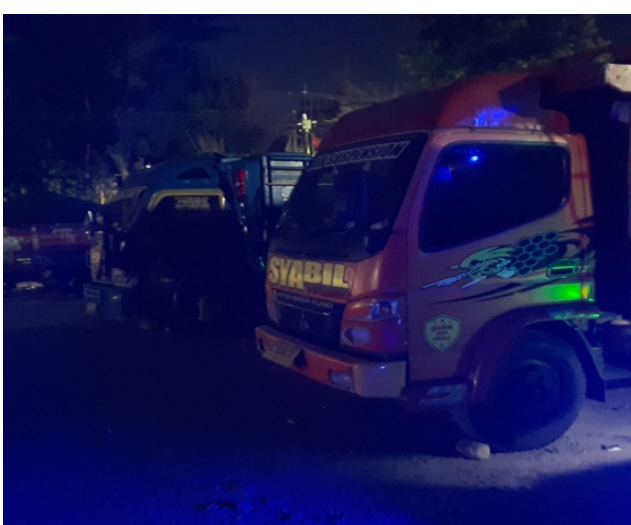

Picture 3. Truck station at night in Batu city.

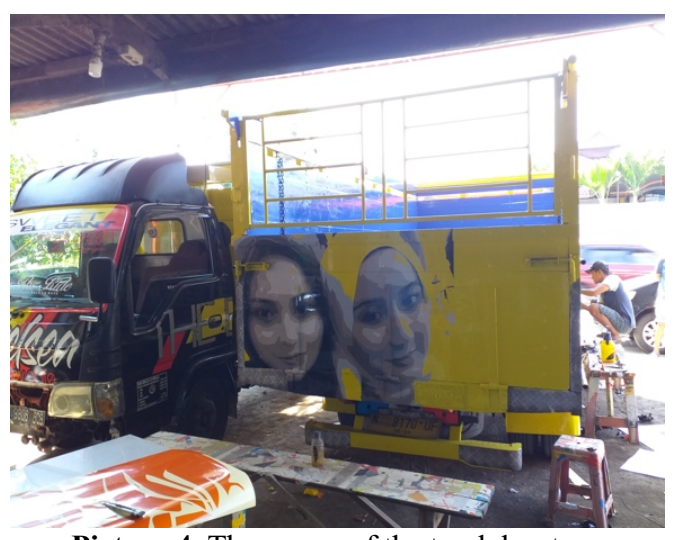

Picture 4. The owner of the truck has two daughters.

Source: Doc. Research team.

The photos of pictures and writings on the tailgates collected during the research and the interviews with different persons in different places found that there are some messages delivered by the truck's drivers or owners to the public. At the utmost of the messages is the identity by showing themselves as a person who has something special and the economic activity with which they are engaged. We can resume the issue of identity by classifying them as follows:

a. The identity of the driver as himself.

b. The economic activity of the driver.

c. The feelings of love for family.

d. The determination to economic survival.

e. The caring for others.

Trucks are large vehicles that have special characteristics with a specific designation as a cargo vehicle. Its large dimensions facilitate people to move goods with a large weight from one area to another. The transport of goods is also carried out between provinces and islands. A driver met in Batu city said that he is from Sumbawa. The truck he drove, carrying a cargo of 12 tones of garlic which transported from Sumbawa to Mojokerto. The journey he took from Sumbawa to Mojokerto was 2 days with several breaks. Such a long journey requires the strength and shrewdness of the driver. Therefore, he put a sticker on the body of the truck with the word "Syabil" a referent to a holy war in the Islamic world, to show the great effort he does to get money from his activity.

A truck with a police number DR indicates that the vehicle originated from West Nusa Tenggara. The truck has striking accessories equipped with headlights mounted on the truck. The head of the truck is also decorated with words such as Blek Tito, Xtreme, as well as CS on the top of the truck head. The driver explained the meaning of the writings that he put on the truck's body as follows: the word Tito refers to an animal like a small snake that lives in Sumbawa and it moved fast in the bush. The writing of "Xtreme" is also intended to show that this vehicle is familiar to go through the extreme places in the mountainous areas. Being used to transport onions, this truck goes in and out of agricultural fields that are located in a 
mountainous area in Sumbawa, at the foot of Tambora. These writings are intended to give a message from the driver to the wider community that the truck he drives is still as agile as Tito even though he is carrying heavy goods and crossing the mountainous extreme places. Also, the word "CS" on the head of the truck is intended to show that this truck and its driver are friendly with anyone they meet and in any place. He will always ready to hang out and be a close friend with people everywhere they meet.

During the pandemic era of Covid-19, the transport of material goods from other places over long distances is not as good as used to be. The drivers have to stay for several days after their arrival before leaving East Java to go back to their home city. At trucks station in Batu city, many drivers have stayed there for several days waiting for goods to be transported to their home city. There are drivers from Borneo, Sumbawa, and also Bali who still waiting for the call of their loyal consumers or their bosses to load materials. This situation gives some negatives impacts due to their revenue that decreases and the high cost that they have to allocate during the waiting. Once they get a call, they load the goods and go back to their home city.

The sentence or word on the tailgate is often a form of expression in a certain local language. An inscription in Javanese found in the tailgate said: "Kuping iso salah ngrungu tapi ati lan perasaan rak bakal iso salah lan diapusi". The ear can hear wrongly but the hearth will not have mistaken. Kuping (ear in Javanese) is the only body organ to hear something. With this sensing tool, someone will get information about whatever is happening around him. However, the message that someone hears can be wrong when the message conveyed by another person is not clear. The reception of a message will not clear when there is an error in the communication channel that connects the sender of the message and the receiver.

Furthermore, this sentence provides a deep moral lesson for everyone. In the Javanese tradition, taking an action is not based on imitates others nor reasoning, but the deep reflection of oneself. By doing these reflections, the results obtained are no longer the temptation of reasoning but came from the heart which contains the truth so that the actions performed will correct and will not be deceived by the false truths.

This phenomenon is certainly interesting to be noted considering that the sending of the messages in the public space is a form of occupation over the public space. Everyone who is passing the road is forced to regard and discern the messages on the writing and pictures that are presented. The public space is a busy place with various visual messages presented by the senders of the message while other members of the community act as a recipient without the possibility to negotiate the message. The road is a public space that full of messages and becomes a showing gallery for the socioeconomic activities of certain people.

\section{Conclusion}

This study found some interesting results that people must comprehend. The tailgate, which has been understood only as a part of a truck where the trucker places the goods to be transported, contains complex ideas that the drivers want to convey to the public. The tailgate serves not only as a place to load some materials goods but also as an aesthetic function to which the owners are willing to put great effort to decorate. It's become a marker of a person's identity, a business entity, a human feeling, and also a marker of one's character. Besides, the body of the truck has an additional economic function as a medium for promoting products and services. The public regards this phenomenon as acceptable for the reason of human nature and its need for aesthetics. 


\section{References}

[1] D. Chandler, Semiotics: the basics, third ed. London; New York: Routledge, 2017.

[2] T. Hawkes, Structuralism and Semiotics. Taylor \& Francis, 2003.

[3] W. Noth, Handbook of semiotics. Indianapolis: Indiana university press, 2014.

[4] U. Eco, A theory of semiotics. Bloomington: Indiana University Press, 1997.

[5] M. Riffaterre, Semiotics of poetry. Bloomington: Indiana University Press, 1984.

[6] M. Carmona, C. de Magalhães, and L. Hammond, Public space: the management dimension. London; New York: Routledge, 2008.

[7] D. Shehayeb, "Safety and Security in Public Space." International Report Crime Prevention And Community Safety: Trends And Perspectives 2008, 2008.

[8] V. W. Turner, The forest of symbols: aspects of Ndembu ritual. Ithaca, N.Y.: Cornell University Press, 2016.

[9] F. de Saussure, Cours de linguistique générale. Paris: Payot, 2016.

[10] D. G. Mick, "Consumer Research and Semiotics: Exploring the Morphology of Signs, Symbols, and Significance," J. Consum. Res., vol. 13, no. 2, pp. 196-213, 1986. 